\title{
Sustainable Development of Sci-Tech Service Intermediaries Based on Triple Helix Model of Innovation
}

\author{
Xiao Yu ${ }^{1}$, Jingdong Yan ${ }^{1 *}$, Fan Zhang ${ }^{1}$, Mushtaq Hamma², Quan Zhang ${ }^{1}$ \\ ${ }^{1}$ School of Management, Wuhan University of Technology, Wuhan 430070, China \\ ${ }^{2}$ School of Business \& Economics, University of Management \& Technology, Lahore 54000, Pakistan \\ Corresponding Author Email: yjd@whut.edu.cn
}

https://doi.org/10.18280/ijsdp.150411

Received: 12 January 2020

Accepted: 27 March 2020

\section{Keywords:}

triple helix model of innovation, sci-tech service intermediaries, sustainable development, evolutionary game

\begin{abstract}
Innovation is an important driver of sci-tech progress. In the innovation network, there are multiple challenges for the cooperation based on sci-tech resources, talents, and sharing mode. To cope with these challenges, it is imperative to promote the sustainable development of scitech service intermediaries, the external institutions that support innovation activities. Based on the triple helix model of innovation, this paper looks for the sustainable development path of sci-tech service intermediaries in the context of openness and innovation. Firstly, neural network analysis was performed to clarify the driving factors and their correlations in innovation activities. Next, the authors established an evolutionary game model of the sustainable development for the sci-tech service intermediary, and used the model to analyze the factors affecting the intermediary's cooperation strategies in innovation activities. After that, the influencing factors of the intermediary's sustainable development were identified through Matlab simulation. The results show that the sustainability of sci-tech service intermediaries depends on the information technology level, resource allocation capability, and operation and management level of its platform.
\end{abstract}

\section{INTRODUCTION}

In the era of knowledge economy, innovation is an important path for a country or region to gain a competitive advantage. Many countries have made innovation the focus of national or regional economic policies, aiming to realize longterm economic growth and recovery. Sci-tech service intermediaries link up the suppliers and consumers of innovation resources, thanks to their abilities to integrate information and resources, identify nonredundant information, expand access to resources, and promote the introduction, transfer, and diffusion of regional innovation resources [1]. With the development of the triple helix model of innovation, innovation subjects in the same region have witnessed changes in their interaction mode and combination structure, resulting in changes in the role of sci-tech service intermediaries [2].

With the development of the triple helix model of innovation, innovation subjects in the same region have witnessed changes in their interaction mode and combination structure, resulting in changes in the role of sci-tech service intermediaries [2]. However, there is still ample room for scitech service intermediaries, facing problems like small scale, limited capacity, and insufficient aggregation, to enhance their supports to innovation activities [3-6]. Therefore, it is imperative to find a solution for sci-tech service intermediaries to realize sustainable development. Drawing on the triple helix model of innovation, this paper introduces the evolutionary game model to analyze the internal dynamic factors of the development of sci-tech service intermediaries, and enable them to achieve sustainable development amidst the increasingly complex innovation activities.
The existing studies on the development of sci-tech service intermediaries mainly focus on role transition and collaborative innovation network. In terms of role transition, sci-tech service intermediaries constantly change their interaction mode with other innovation subjects, and extend their business scope to the upstream and downstream of the innovation chain. Over the time, these intermediaries gradually evolve into media, knowledge disseminators, or integrated service providers [7]. As the media, sci-tech service intermediaries act as a bridge between research institutes, technical institutions, and enterprises, which effectively reduces the acquisition cost of innovation resources, and promotes the willingness of enterprises to communicate and cooperate [8]. Their business operations could create a longawaited channel for information dissemination between the government and small and medium-sized enterprises (SMEs) [9]. As knowledge disseminators, sci-tech service intermediaries accumulate and master lots of heterogeneous information through frequent contacts with enterprises and research institutions, facilitating the enterprises to obtain nonredundant new knowledge and expand their knowledge reserves $[10,11]$. As integrated service providers, sci-tech service intermediaries provide rich and diverse services in a systematic manner, fulfilling the demand for overall development of regional innovation system [12]. The diversification of sci-tech service intermediaries helps to stick regional innovation subjects together, and forge a common knowledge base for regional innovation system [13, 14].

In terms of collaborative innovation network, sci-tech service intermediaries are essential to the innovation system [15]. The higher the density of the network, the more likely it 
is for network members to develop mutual trust, formulate recognized norms, and improve the overall performance [16]. Smits and Kuhlmann [17] suggested that sci-tech service intermediaries are mainly responsible for laying a strategic intellectual foundation for the innovation system. Kivimaa [18] pointed out that intermediaries with government background can promote systemic sustainable development through the management of sci-tech policies. Jiang and Mei [19] held that the unique attributes of sci-tech service intermediaries help to overcome three obstacles in regional innovation, namely, information asymmetry, information isolated island, and professional divide, thereby promoting the effective operation of regional innovation system, and enhancing the coupling mechanism of regional innovation capabilities.

Since its proposal by Leydesdorff and Etzkowitz, the triple helix model has been constantly improved [20-22]. The core of the model is to build an institutional foundation for innovation development $[23,24]$. The triple helix model considers the complex innovation process as a trilateral network of constant interactions between the spheres of industry, university, and government, rather than an event involving a single innovation subject. The three spheres are closely combined into a triple helix structure. In the triple helix model, each sphere is assigned a specific role to constitute an innovation system. The scopes of the spheres are changed and rebalanced continuously [25]. For example, the university may set up affiliated industries, large and small enterprises may form strategic alliances, and the government may operate labs and organize academic research groups. As the functions of the three spheres overlap each other, the roles of industry, university, and government will change in the overlapping areas.

In general, there are three forms of the triple helix model: centralized, free, and balanced [26]. In the centralized triple helix model (Figure 1a), the government organizes and controls industry and university, and strictly supervises the interaction between the two. In the free triple helix model (Figure 1b), industry, university and government have clearly divided functions, and very limited interactions. In the balanced triple helix model (Figure 1c), the boundaries of industry, university, and government are blurred through cooperation, exchanges, and role transitions. With the elapse of time, the scopes of the three spheres overlap and penetrate each other. Hence, various functions are organized organically, enhancing factor integration, resource sharing, and innovation efficiency. In this process, the three spheres keep adjusting their own functions and structures, while maintaining their independence. Overall, the entire innovation system exists as a triple helix, in which the members support each other and develop across borders. The balanced form is the closet to the original triple helix model designed by Etzkowitz and Leydesdorff. Most countries and regions adopt this form of the triple helix model.

Based on the balanced triple helix model of innovation, this paper takes the hybrid organization in the innovation network as the cooperation object of a sci-tech service intermediary, and constructs an evolutionary game model of the sustainable development for the sci-tech service intermediary from the perspective of triple helix. The established model was used to discuss the cooperation strategies of the sci-tech service intermediary in innovation activities, such as to promote the sustainable development of technical innovation. To the best of our knowledge, it is the first time that the hybrid organization in the triple helix model, i.e. the trilateral network formed through the role transitions of the spheres in the triple helix model of innovation, is treated as an innovation subject.

The remainder of this paper is organized as follows: Section 2 relies on neural network analysis to clarify the driving factors and their correlations in innovation activities; Section 3 sets up an evolutionary game model of the sustainable development for the sci-tech service intermediary from the perspective of triple helix, and establishes the profit matrix of the cooperation strategies; Section 4 verifies the stability of the proposed model, and applied the model to simulation analysis; Section 5 summarizes the key factors in the sustainable development of sci-tech service intermediaries, and puts forward the conclusions.

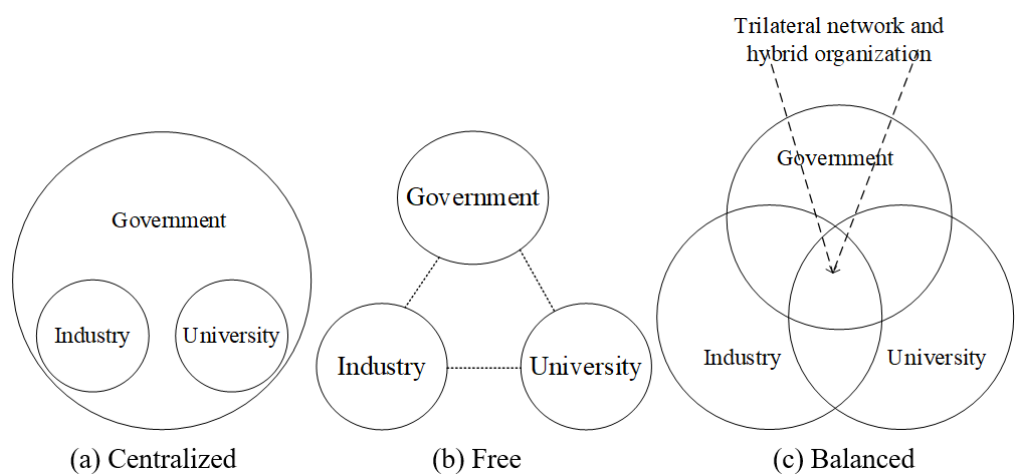

(a) Centralized

(b) Free

(c) Balanced

Figure 1. Three forms of the triple helix model

\section{NEURAL NETWORK ANALYSIS ON DRIVING FACTORS OF INNOVATION ACTIVITIES}

Based on network theory of system engineering, the neural network integrates multiple disciplines and mimics the basic functions of the human brain. It is a highly-responsible nonlinear dynamic learning system, capable of distributed storage and parallel processing of information. The neural network is suitable for handling fuzzy problems with many factors and constraints. Artificial neural networks have many advantages in information processing, such as nonlinear mapping, good fault tolerance, strong adaptability, and associative storage. Thanks to these advantages, the neural network can fully consider the correlations between various factors, reflect their mutual influence and constraints, and examine the nonlinear transmission and actions of them in the same network.

In innovation activities, the cooperation between a sci-tech 
service intermediary and the hybrid organization in the triple helix model is affected by multiple factors. Inspired by the nonlinear processing of the neural network, two frameworks (Figure 2) were developed to illustrate the factors affecting the participation of the sci-tech service intermediary and the hybrid organization, as two independent subjects, in the innovation activities.

As shown in Figure 2, the sci-tech service intermediary and the hybrid organization are in the center of the two rings, respectively. The factors affecting their participation in innovation activities not only act on the two centers, but also interact with each other. The framework design visually displays the driving factors of each innovation subject and the correlations between these factors, laying a solid basis for the subsequent analysis.
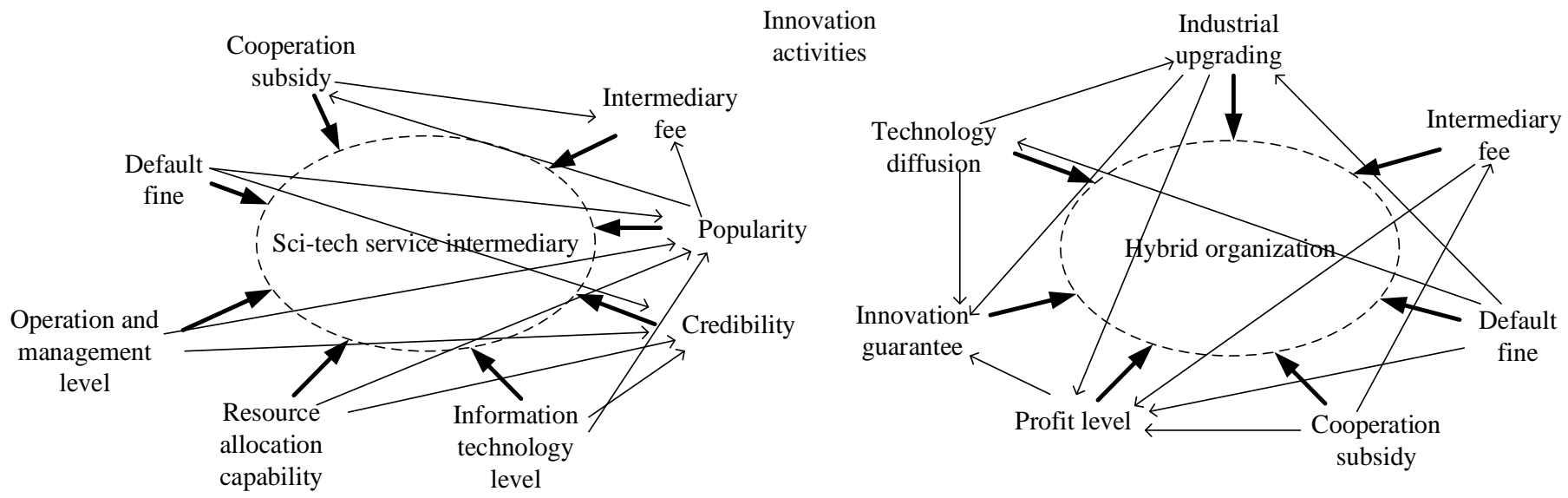

Figure 2. Frameworks of factors affecting innovation activities

\section{EVOLUTIONARY GAME MODEL OF SUSTAINABLE DEVELOPMENT FOR SCI-TECH SERVICE INTERMEDIARY}

During the dynamic process of an evolutionary game, the evolutionarily stable strategy (ESS) depends on the initial conditions and the evolutionary path. Drawing on the replicator dynamics of evolutionary game theory, this paper assumes that the two innovation subjects have bounded rationality. In a dynamically changing environment, the two game players, i.e. the sci-tech service intermediary and the hybrid organization, keep making decisions on whether to implement sci-tech cooperation until the proportion of cooperation behavior tends to be stable.

\subsection{Basic hypotheses}

H1. The strategy space of the sci-tech service intermediary $\mathrm{A}$ and the hybrid organization $\mathrm{B}$ is \{cooperation, noncooperation $\}$.

$\mathrm{H} 2$. The net profits of $\mathrm{A}$ and $\mathrm{B}$ in noncooperation are $\mathrm{A}_{1}$ and $\mathrm{B}_{1}$, respectively.

$\mathrm{H} 3$. The profits of $\mathrm{A}$ and $\mathrm{B}$ through cooperation include direct profits $A_{2}$ and $B_{2}$, and indirect profits $A_{3}$ and $B_{3}$. For $A$, the direct profit $A_{2}$ is the intermediary fee collected for its services, and the indirect profit $\mathrm{A}_{3}$ is the popularity and credibility of the platform. With the growing indirect profit of $\mathrm{A}$, the business volume and radiation area of the platform will both increase. Focusing on the cooperation strategies of A, this research will not tackle the direct or indirect profit of the hybrid organization.

$\mathrm{H} 4$. The costs of $\mathrm{A}$ and $\mathrm{B}$ through cooperation are $\mathrm{A}_{4}$ and $\mathrm{B}_{4}$, respectively. For $\mathrm{A}$, the cost $\mathrm{A}_{4}$ is mainly affected by three factors of the platform, namely, information technology level, resource allocation capability, and operation and management level. The higher the information technology level, the lower the unit cost, and the faster the creation of sci-tech resources. The stronger the resource allocation capability, the more efficiently the platform allocates the resources. The more scientific the operation and management, the lower the cost of A. For $B$, the cost $\mathrm{B}_{4}$ is the intermediary fee.

H5. After A and B both chose cooperation, if one party breaches the contract, this party should pay a default fine $\mathrm{P}$ to the other party; the subsidy, fund, and other benefits brought by the cooperation between $\mathrm{A}$ and $\mathrm{B}$ are denoted as $\mathrm{F}$.

H6. The probabilities for A and B to choose cooperation are $\mathrm{x}$ and $\mathrm{y}$, respectively; the probabilities for $\mathrm{A}$ and $\mathrm{B}$ to choose noncooperation are $1-\mathrm{x}$ and $1-\mathrm{y}$, respectively; $\mathrm{x}$ and $\mathrm{y} \in[0,1]$.

\subsection{Model construction}

Under the dynamically changing environment (information exchange, resource complementation, and profits), A and B continue to decide on whether to cooperate with each other until the optimal strategy tends to be stable. Based on the above hypotheses, a profit matrix was established (Table 1) for the cooperation strategies of A from the perspective of triple helix.

\section{EXAMPLE ANALYSIS}

\subsection{Local stability analysis}

The dynamic evolution of the cooperation strategies between $\mathrm{A}$ and $\mathrm{B}$ was described based on the above profit matrix and replicator dynamics functions. The first step is to construct the expected profit functions. 
Table 1. The profit matrix of A's cooperation strategies from the perspective of triple helix

\begin{tabular}{lccc}
\hline \multirow{2}{*}{$\mathrm{A}$} & $\mathrm{B}$ & \multicolumn{2}{c}{ The hybrid organization } \\
\cline { 3 - 4 } Sci-tech service intermediary & Cooperation & $\mathrm{A}_{1}+\mathrm{A}_{2}+\mathrm{A}_{3}-\mathrm{A}_{4}+\mathrm{F} ; \mathrm{B}_{1}+\mathrm{B}_{2}+\mathrm{B}_{3}-\mathrm{B}_{4}+\mathrm{F}$ & $\mathrm{A}_{1}-\mathrm{A}_{4}+\mathrm{P} ; \mathrm{B}_{1}-\mathrm{P}$ \\
& Noncooperation & $\mathrm{A}_{1}-\mathrm{P} ; \mathrm{B}_{1}-\mathrm{B}_{4}+\mathrm{P}$ & $\mathrm{A}_{1} ; \mathrm{B}_{1}$ \\
\hline
\end{tabular}

If $\mathrm{A}$ chooses cooperation, the expected profit is $U_{A \text { cooperation }}=y\left(A_{1}+A_{2}+A_{3}-A_{4}+F\right)+(1-y)\left(A_{1}-\right.$ $\left.A_{4}+F\right)$; If A chooses noncooperation, the expected profit is $U_{A \text { cooperation }}=y\left(A_{1}-P\right)+(1-y) A_{1}$. Then, the mean profit of $\mathrm{A}$ is $\overline{\mathrm{U}}_{A}=x U_{A \text { cooperation }}+(1-x) U_{A \text { nocooperation. }}$

Based on the expected profit and mean profit of A choosing cooperation, the replicator dynamics function of A choosing cooperation can be constructed as:

$$
\begin{gathered}
f(x, y)=\frac{d x}{d t}=x\left(U_{A \text { cooperation }}-\overline{\mathrm{U}}_{A}\right)=x(1- \\
x)\left(y A_{2}+y A_{3}+y F-A_{4}+P\right)
\end{gathered}
$$

If $B$ chooses cooperation, the expected profit is $U_{B \text { cooperation }}=x\left(B_{1}+B_{2}+B_{3}-B_{4}+F\right)+(1-x)\left(B_{1}-\right.$ $B_{4}+F$ ); If $B$ chooses noncooperation, the expected profit is $U_{B \text { nocooperation }}=x\left(B_{1}-P\right)+(1-x) B_{1}$. Then, the mean profit of B is $\bar{U}_{B}=y U_{B \text { cooperation }}+(1-y) U_{B}$ nocooperation.

Similarly, the replicator dynamics function of $\mathrm{B}$ choosing cooperation can be constructed as:

$$
J=\mid \begin{gathered}
(1-2 x)\left[y\left(A_{2}+A_{3}+F\right)-A_{4}+P\right] \\
y(1-y)\left(B_{2}+B_{3}+F\right)
\end{gathered}
$$

The determinant and trace of matrix $\mathrm{J}$ can be respectively expressed as:

$\operatorname{det}(J)=(1-2 x)\left[y\left(A_{2}+A_{3}+F\right)-A_{4}+P\right](1-$

2y) $\left[x\left(B_{2}+B_{3}+F\right)-\mathrm{B}_{4}+P\right]-x(1-x)\left(A_{2}+A_{3}+\right.$ $F) y(1-y)\left(B_{2}+B_{3}+F\right)\left(x-x_{0}\right)$,

$\operatorname{tr}(J)=(1-2 x)\left[y\left(A_{2}+A_{3}+F\right)-A_{4}+P\right]+(1-$

$2 y)\left[x\left(B_{2}+B_{3}+F\right)-B_{4}+P\right]$.

Next, the five equilibrium points were subjected to local stability analysis of the Jacobian matrix. The analysis results are listed in Table 2.

Table 2. Results of local stability analysis

\begin{tabular}{cccc}
\hline Equilibrium points & $\begin{array}{c}\text { Sign of } \\
\text { determinant }\end{array}$ & $\begin{array}{c}\text { Sign of } \\
\text { trace }\end{array}$ & Results \\
\hline $\mathrm{O}(0,0)$ & + & - & ESS \\
$\mathrm{C}(0,1)$ & + & + & Unstable \\
$\mathrm{A}(1,0)$ & + & + & Unstable \\
$\mathrm{B}(1,1)$ & + & - & ESS \\
$\mathrm{D}\left(\frac{\mathrm{B}_{4}-\mathrm{P}}{\mathrm{B}_{2}+\mathrm{B}_{3}+\mathrm{F}}, \frac{\mathrm{A}_{4}-\mathrm{p}}{\mathrm{A}_{2}+\mathrm{A}_{3}+\mathrm{F}}\right)$ & - & 0 & $\begin{array}{c}\text { Saddle } \\
\text { point }\end{array}$ \\
\hline
\end{tabular}

As shown in Table 2, local equilibrium points $\mathrm{O}$ and $\mathrm{B}$ are the stable points of the game, corresponding to strategies \{cooperative, cooperative\} and \{non-cooperative, noncooperative\}, respectively.

By contrast, local equilibrium points $\mathrm{C}$ and $\mathrm{A}$ are unstable points of the game, corresponding to strategies \{noncooperative, cooperative\} and \{cooperative, non-cooperative\}. In addition, local equilibrium point $\mathrm{E}$ is the saddle point, i.e. the critical point of the game.

$$
\begin{gathered}
g(x, y)=\frac{d y}{d t}=y\left(U_{B \text { cooperation }}-\overline{\mathrm{U}}_{B}\right)=y(1- \\
y)\left(x B_{2}+B_{3}-x F-B_{4}+P\right)
\end{gathered}
$$

The decisions of $\mathrm{A}$ and $\mathrm{B}$ will eventually reach a Nash equilibrium, due to environmental changes and continuous learning and communication. Thus, the equilibrium point of the game can be calculated by:

$$
f(x, y)=\frac{d x}{d t}=0 ; g(x, y)=\frac{d y}{d t}=0 .
$$

From the above, five local equilibrium points can be identified for the game between A and B: $(0,0),(0,1),(1,0)$, $(1,1)$ and $\left(\frac{B_{4}-P}{B_{2}+B_{3}+F}, \frac{A_{4}-p}{A_{2}+A_{3}+F}\right)$.

Through Taylor series expansion of (1) and (2), the approximate linear equations of (1) and (2) at the equilibrium point $\left(\mathrm{x}_{0}, \mathrm{y}_{0}\right)$ can be derived:

$$
\begin{aligned}
& \quad \frac{d x}{d t}=(1-2 x)\left[y\left(A_{2}+A_{3}+F\right)-\mathrm{A}_{4}+P\right]\left(x-x_{0}\right)+ \\
& x(1-x)\left(A_{2}+A_{3}+F\right)\left(y-y_{0}\right), \\
& \quad \frac{d y}{d t}=y(1-y)\left(B_{2}+B_{3}+F\right)\left(x-x_{0}\right)+(1-2 y)\left[x \left(B_{2}+\right.\right. \\
& \left.\left.B_{3}+F\right)-\mathrm{B}_{4}+P\right]\left(y-y_{0}\right) .
\end{aligned}
$$

Then, the Jacobian matrix can be obtained as:

$$
\begin{gathered}
x(1-x)\left(A_{2}+A_{3}+F\right) \\
(1-2 y)\left[x\left(B_{2}+B_{3}+F\right)-B_{4}+P\right]
\end{gathered}
$$

\subsection{Phase diagram analysis}

Based on the stability analysis on local equilibrium points, a phase diagram (Figure 3) was plotted to illustrate the dynamic evolution of the cooperation strategies between $\mathrm{A}$ and $\mathrm{B}$.

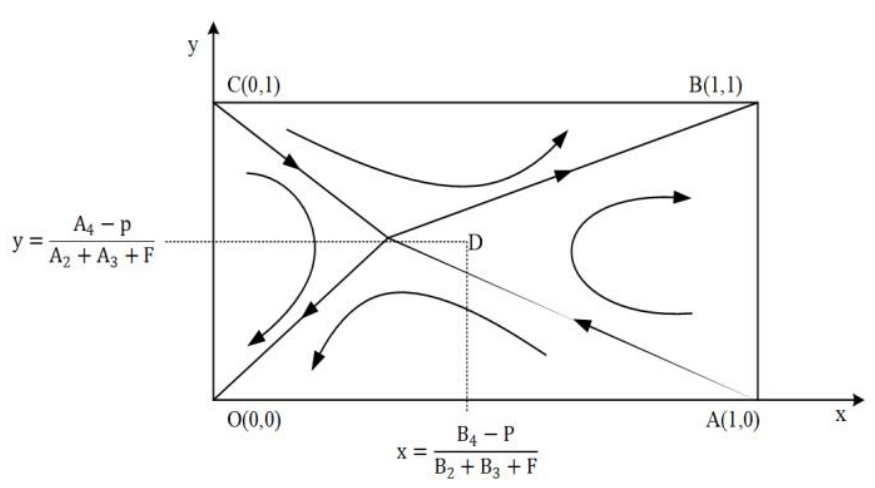

Figure 3. The phase diagram of strategy evolution

Whether A chooses cooperation mainly depends on the ratio of profit to cost. Therefore, any change to the profit matrix and its parameters will directly affect A's selection of cooperation strategy, causing the strategies of A and B to evolve towards different equilibrium points.

The critical line between the behaviors of $\mathrm{A}$ and $\mathrm{B}$ connects unstable points $\mathrm{A}$ and $\mathrm{C}$ through the saddle point $\mathrm{D}$. If the initial state of the game falls in OADC, the cooperation strategies of $A$ and $B$ will converge to the stable point $O(0,0)$, i.e. both $\mathrm{A}$ and $\mathrm{B}$ choose noncooperation. If the initial state of 
the game falls in $\mathrm{CDAB}$, the cooperation strategies of $\mathrm{A}$ and $\mathrm{B}$ will converge to the stable point $B(1,1)$, i.e. both $A$ and $B$ choose cooperation. In this case, the two parties will achieve coordinated development through cooperation.

Based on the analysis of the evolutionary game model, the cooperation strategies of A and B could both eventually stabilize as cooperation or noncooperation. This is mainly related to the change of parameters in the profit matrix. Therefore, the key factors affecting A's cooperation strategies were analyzed in details below:

\section{(1) Cooperation cost}

If the cooperation cost grows, the CDAB area will continue to expand, and the two parties will be more likely to choose noncooperation. Then, the probability that the game evolves toward the stable point of \{noncooperation, noncooperation\} will increase. If the cooperation cost falls, the CDAB area will continue to shrink, and the two parties will be more likely to choose cooperation. Then, the probability that the game evolves towards the stable point of \{cooperation, cooperation\} will increase. Therefore, the two parties should reduce the cost and risk of cooperation, so that the game evolves towards \{cooperation, cooperation .

For A, the cooperation cost is mainly affected by the information technology level, resource allocation capability, and operation and management level of the platform. First, A should reduce the cooperation cost by improving the level of information technology of its platform. The higher the information technology level, the platform is more likely to provide high-quality sci-tech resources and services at a low cost. As a result, high-tech resources could be created more efficiently, fulfilling the diverse and complex technical demand. Second, the cooperation cost should be reduced by enhancing the resource allocation capability. A strong capability of resource allocation helps to integrate sci-tech resources efficiently, improve service quality, and strengthen the complementarity of resources. Third, A should also operate and manage its platform more efficiently to further reduce its cooperation cost. For B, the cooperation cost decreases with the intermediary fee.

To sum up, in our model, A should improve the information technology level, resource allocation capability, and operation and management level of the platform, and charge a proper amount of intermediary fee, thereby reducing the cooperation costs of both parties. These efforts could push the saddle point $\mathrm{D}$ towards the stable point $\mathrm{A}(0,0)$, and expand the area of $\mathrm{CDAB}$, i.e. increase the probability for both $\mathrm{A}$ and $\mathrm{B}$ to choose cooperation.

\section{(2) Default fine}

As shown in the phase diagram, the evolution directions of the two parties hinges on the areas of OADC and CDAB. The area of OADC can be calculated by $S=\frac{1}{2}\left(\frac{A_{4}-P}{A_{2}+A_{3}+F}+\right.$ $\left.\frac{B_{4}-P}{B_{2}+B_{3}+F}\right)$. Deriving $P$ by the area formula $S$, we have $\frac{\partial_{S}}{\partial_{P}}=$ $-\frac{1}{2}\left(\frac{1}{\mathrm{~A}_{2}+\mathrm{A}_{3}+\mathrm{F}}+\frac{1}{\mathrm{~B}_{2}+\mathrm{B}_{3}+\mathrm{F}}\right)<0$. Obviously, $\mathrm{S}$ is a decreasing function of $\mathrm{P}$. If the default fine increases, the OADC area will shrink, and the two parties will be more likely to choose cooperation. Then, the game will evolve towards \{cooperation, cooperation $\}$ at a greater probability. Thus, the two parties should properly increase the default fine $\mathrm{P}$ to promote the evolution towards \{cooperation, cooperation\}.

(3) Cooperation subsidy

Deriving $F$ by the area formula $S$, we have $\frac{\partial_{\mathrm{S}}}{\partial_{\mathrm{F}}}=$
$-\frac{1}{2}\left(\frac{A_{4}-P}{\left(A_{2}+A_{3}+F\right)^{2}}+\frac{B_{4}-P}{\left(B_{2}+B_{3}+F\right)^{2}}\right)<0$. Obviously, $S$ is a decreasing function of $F$. If the third-party subsidy increases, the OADC area will shrink, and the two parties will be more likely to choose cooperation. Then, the game will evolve towards \{cooperation, cooperation\} at a greater probability. Thus, the two parties should properly increase the subsidy to deepen cooperation.

\subsection{Numerical simulation}

According to previous hypothesis, Matlab simulation was performed to reveal how initial state and relevant factors affect the game evolution and the stability of cooperation strategies. Based on Figure 3, three factors were selected for simulation: cooperation cost $\mathrm{A}_{4}$, default fine $\mathrm{P}$, and cooperation subsidy $\mathrm{F}$.

(1) Cooperation cost $\mathrm{A}_{4}$

During the simulation of cooperation cost $A_{4}$, the parameters were configured as: $A_{1}=8, B_{1}=12, A_{2}=20, B_{2}=25$, $\mathrm{A}_{3}=10, \mathrm{~B}_{3}=15, \mathrm{~B}_{4}=15, \mathrm{~F}=30$, and $\mathrm{P}=32$. Under the game constraints, the value of $\mathrm{A}_{4}$ should fall in $(0,16)$. Hence, the value of $A_{4}$ was simulated at 10,12,13, and 15. Figure 4 shows how the variation of $\mathrm{A}_{4}$ affects the cooperation strategies. It can be seen that, with the gradual increase of $\mathrm{A}_{4}$, A tended to choose noncooperation. The willingness to cooperate of $\mathrm{A}$ is negatively correlated with cooperation cost.

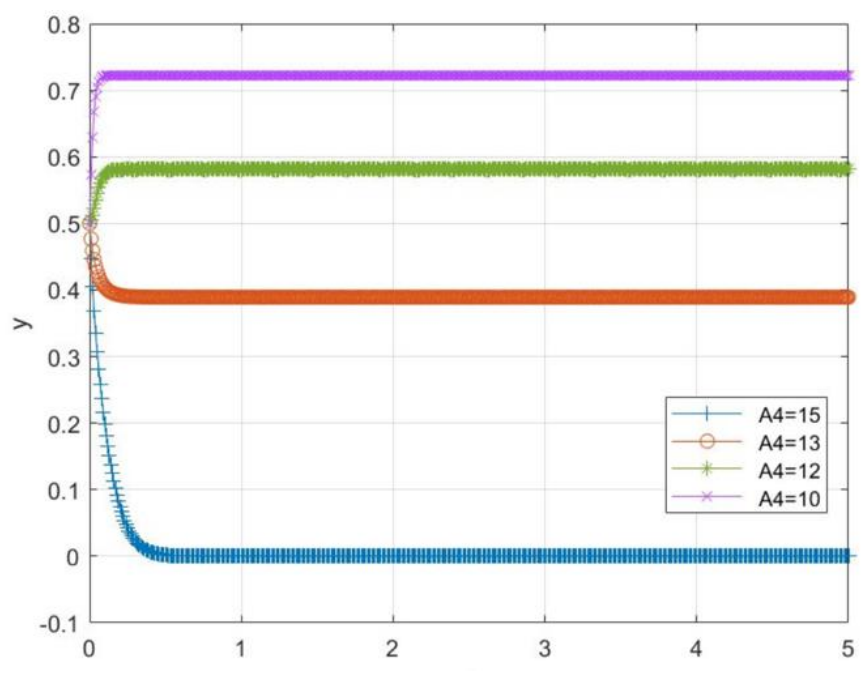

Figure 4. Evolution of cooperation strategies with the change of $\mathrm{A}_{4}$

\section{(2) Default fine $P$}

During the simulation of default fine $\mathrm{P}$, the parameters were configured as: $A_{1}=8, B_{1}=12, A_{2}=20, B_{2}=25, A_{3}=10, B_{3}=15$, $\mathrm{A}_{4}=12, \mathrm{~B}_{4}=15$, and $\mathrm{F}=30$. Under the game constraints, the value of $P$ should fall in $(3,9)$. Hence, the value of $P$ was simulated at 6,7 , and 8 . Figure 5 shows how the variation of $\mathrm{P}$ affects the cooperation strategies. It can be seen that, with the growth of $\mathrm{P}$, the cooperation between the two parties stabilized at an increasingly fast rate. This means default fine restricts the two parties to a certain extent.

(3) Cooperation subsidy F

During the simulation of cooperation subsidy $\mathrm{F}$, the parameters were configured as: $A_{1}=8, B_{1}=12, A_{2}=20, B_{2}=25$, $\mathrm{A}_{3}=10, \mathrm{~B}_{3}=15, \mathrm{~A}_{4}=12, \mathrm{~B}_{4}=15$, and $\mathrm{P}=32$. Under the game constraints, the value of $P$ should fall in $(2,8)$. Hence, the value of $\mathrm{P}$ was simulated at 5, 6, and 7. Figure 6 shows how the variation of $\mathrm{F}$ affects the cooperation strategies. It can be seen 
that, with the growth of $\mathrm{F}$, the cooperation between the two parties became more and more stable. Thus, cooperation subsidy, as part of profit, promotes the stability of the cooperation between the two parties.

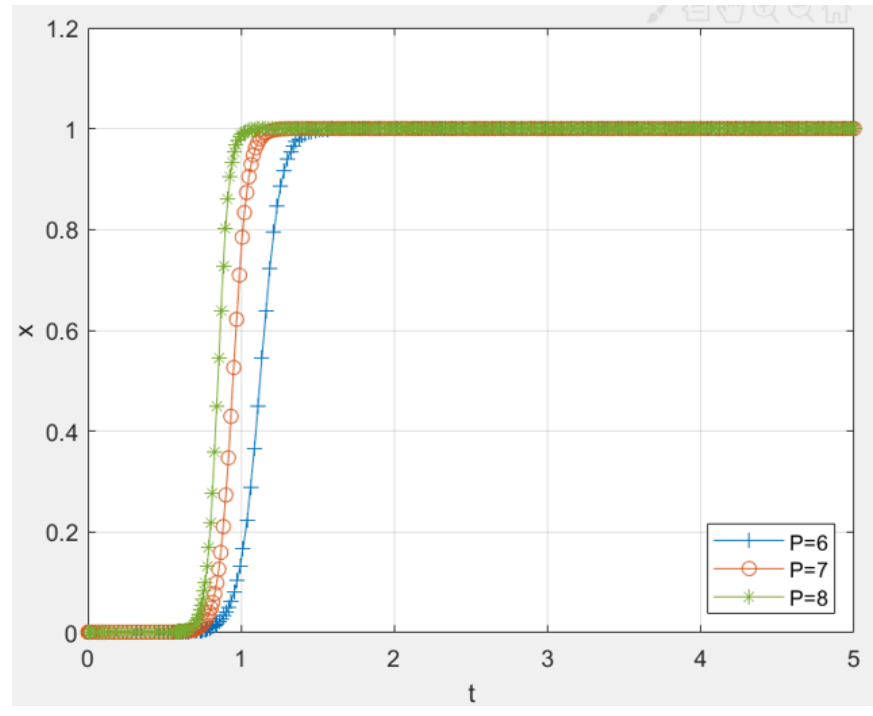

Figure 5. Evolution of cooperation strategies with the change of $\mathrm{P}$

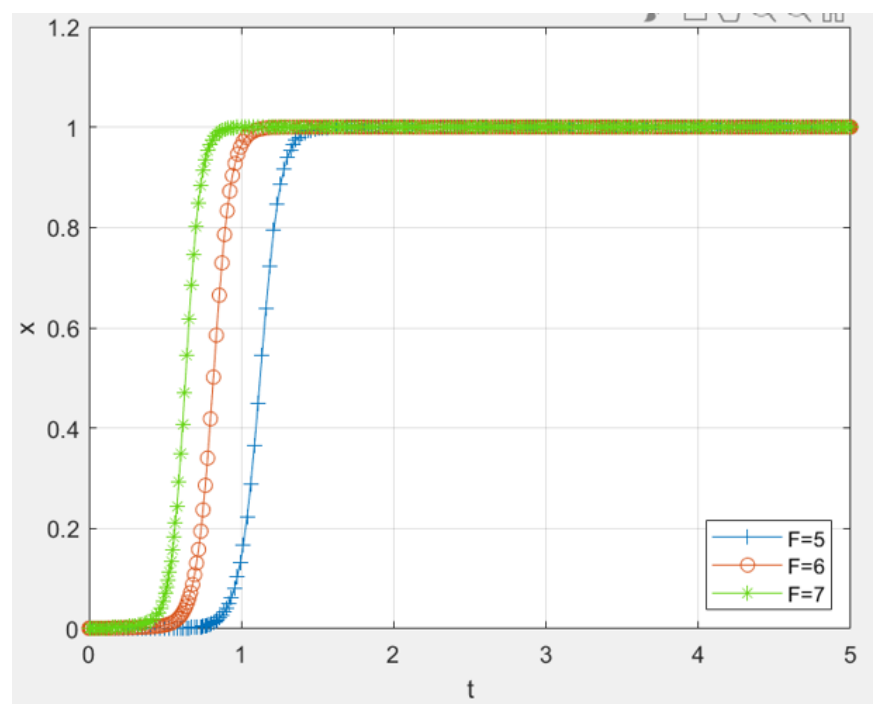

Figure 6. Evolution of cooperation strategies with the change of $\mathrm{F}$

\section{CONCLUSIONS}

Based on the triple helix model of innovation, this paper adopts evolutionary game model to analyze the sustainable cooperation strategies of sci-tech service intermediaries in innovation activities. Through the analysis, the authors identified the factors that promote sci-tech service intermediaries to choose cooperation in innovation activities. The results show that, to enhance the national/regional innovation vitality, sci-tech service intermediaries should improve the information technology level, resource allocation capability, and operation and management level of its platform; these efforts can effectively promote the willingness of scitech service intermediaries to cooperate with the hybrid organization in innovation activities. Moreover, the sustainability of sci-tech service intermediaries could be improved by increasing default fine, government subsidy, and third-party fund. It should be noted that our evolutionary game model does not consider information asymmetry. The future research will further investigate the cooperation strategies of sci-tech service intermediaries in sci-tech innovation, giving full play to their promoting effects on innovation activities.

\section{ACKNOWLEDGEMENTS}

This study was supported by National Key R\&D Program of China (Grant No. 2018YFB140430405).

\section{REFERENCES}

[1] Howells, J. (2006). Intermediation and the role of intermediaries in innovation. Research Policy, 35(5): 715-728. https://doi.org/10.1016/j.respol.2006.03.005

[2] Mcadam, M., Debackere, K. (2018). Beyond 'triple helix' toward 'quadruple helix' models in regional innovation systems: implications for theory and practice: Beyond 'triple helix' toward 'quadruple helix' models. R\&D Management, 48: 3-6. https://10.1111/radm.12309

[3] Wang, S.H., Wang, S.Y. (2018). Research on coordinative growth of regional science and technology intermediary service organizations. On Economic Problems, (10): 105-109. https://10.16011/j.cnki.jjwt.2018.10.019

[4] Lv, W., Fa, R. (2019). Research on the construction of science and technology intermediary service system from the perspective of innovation demand in Shanxi. Journal of Technical Economics \& Management, (10): 39-45.

[5] Kant, M., Kanda, W. (2019). Innovation Intermediaries: what does it take to survive over time? Journal of Cleaner Production, 229:

911-930. https://doi.org/10.1016/j.jclepro.2019.04.213

[6] Kanda, W., Rio, P., Hjelm, O., Bienkowska, D. (2019). A technological innovation systems approach to analyse the roles of intermediaries in eco-innovation. Journal of Cleaner Production, 227: 1136-1148. https://doi.org/10.1016/j.jclepro.2019.04.230

[7] Guo, Y.Y., He, Y.N., Cheng, C., Xu, Z.Y. (2019). The interaction mechanism between evolution of the roles S\&T intermediary plays and network structure in cluster. Studies in Science of Science, 37(3): 450-461. https://10.16192/j.cnki.1003-2053.2019.03.008

[8] Lin, M., Wei, J. (2018). The impact of innovation intermediary on knowledge transfer. Physica A: Statistical Mechanics and its Applications, 502: 21-28. https://doi.org/10.1016/j.physa.2018.02.207

[9] Hossain, M. (2017). Motivations, challenges, and opportunities of successful solvers on an innovation intermediary platform. Technological Forecasting and Social Change, 128: 67-73. https://doi.org/10.1016/j.techfore.2017.10.018

[10] Randhawa, K., Wilden, R., Gudergan, S. (2018). Open service innovation: The role of intermediary capabilities. Journal of Product Innovation Management, 35: 808-838. https://doi.org/10.1111/jpim.12460

[11] Stezano, F. (2018). The role of technology centers as intermediary organizations facilitating links for innovation: Four cases of federal technology centers in 
Mexico. Review of Policy Research, 35(4): 642-666. https://doi.org/10.1111/ropr.12293

[12] Chen, J.L., Qi, G.J., Zhou, R. (2018). The building mechanism and evolution process of innovation intermediary capability based on open innovation platform: A case study of Zoneyan. Forum on Science and Technology in China, (10): 62-72. https://10.13580/j.cnki.fstc.2018.10.008

[13] Knockaert, M., Spithoven, A., Clarysse, B. (2014). The impact of technology intermediaries on firm cognitive capacity additionality. Technological Forecasting and Social Change, 81: 376-387.

[14] De Silva, M., Howells, J., Meyer, M. (2018). Innovation intermediaries and collaboration: Knowledge-based practices and internal value creation. Research Policy, 47(1): 70-87. https://10.1016/j.respol.2017.09.011

[15] Watkins, A., Papaioannou, T., Mugwagwa J., Kale, D. (2015). National innovation systems and the intermediary role of industry associations in building institutional capacities for innovation in developing countries: A critical review of the literature. Research Policy, 44(8): 1407-1418. https://doi.org/10.1016/j.respol.2015.05.004

[16] Wu, B. (2017). From individual social capital to collective social capital: Empirical evidence from interfirm financing trust networks. Sociological Studies, 32(01): 125-147. https://10.1186/s40711-018-0088-3

[17] Smits, R., Kuhlmann, S. (2004). The rise of systemic instruments in innovation policy. International Journal of Foresight and Innovation Policy, 1(1-2): 4-32. https://10.1504/IJFIP.2004.004621

[18] Kivimaa, P. (2014). Government-affiliated intermediary organisations as actors in system-level transitions. Research Policy, 43(8): 1370-1380. https://doi.org/10.1016/j.respol.2014.02.007
[19] Jiang, Y.K., Mei, Q. (2014). Research on coupling mechanism of science and technology intermediary's characteristics and regional innovation capability. Scientific Management Research, 32(3): 72-75. https://10.19445/j.cnki.15-1103/g3.2014.03.019

[20] Leydesdorff, L., Meyer, M. (2003). Triple helix of university-industry-government relations. Scientometrics, 58 : https://10.1023/A:1026276308287

[21] Leydesdorff, L., Etzkowitz, H. (1998). The triple helix as a model for innovation studies. Science and Public Policy, 25: 195-203. https://10.1093/spp/25.3.195

[22] Etzkowitz, H., Leydesdorff, L. (2000) The dynamics of innovation: From national systems and "Mode 2" to a triple helix of university-industry-government relations. Research Policy, 29(2): 109-123. https://doi.org/10.1016/S0048-7333(99)00055-4

[23] Fogelberg, H., Thorpenberg, S. (2012). Regional innovation policy and public--private partnership: The case of triple helix arenas in Western Sweden. Science and Public Policy, 39(3): 347-356. https://10.1093/scipol/scs023

[24] Hotz-Hart, B., Rohner, A. (2014). Nationen im Innovationswettlauf: Die Gewichte verschieben sich. Nationen im Innovationswettlauf, 295-320. https://10.1007/978-3-658-03081-0_13

[25] Leydesdorff, L., Etzkowitz, H. (1998). The Triple Helix as a model for innovation studies. Science and Public Policy, 25: 195-203. https://10.1093/spp/25.3.195

[26] Ranga, M., Etzkowitz, H. (2013). Triple helix systems: An analytical framework for innovation policy and practice in the knowledge society. Industry and Higher Education, 27(4): 237-262. https://10.5367/ihe.2013.0165 